\title{
A Novel Carbohydrate-deficient Glycoprotein Syndrome Characterized by a Deficiency in Glucosylation of the Dolichol-linked Oligosaccharide
}

\author{
Patricie Burda, ${ }^{\star}$ Lubor Borsig, ${ }^{\ddagger}$ Joanneke de Rijk-van Andel, ${ }^{\S}$ Ron Wevers, Jaak Jaeken, ${ }^{\mathbb{}}$ H. Carchon, "Eric G. Berger, ${ }^{\ddagger}$ \\ and Markus Aebi* \\ *Microbiology Institute, ETH Zurich, ETH Zentrum, CH-8092 Zurich, Switzerland; ${ }^{\ddagger}$ Institute of Physiology, University of Zurich, \\ Winterthurerstrasse 190, CH-8057 Zurich, Switzerland; ${ }^{\S}$ Department of Neurology, Ignatius Hospital, Molengracht 21, 4818 CK Breda, \\ The Netherlands; "Laboratory of Pediatrics and Neurology, University of Nijmegen, 6525 HP Nijmegen, The Netherlands; ${ }^{\circledR C}$ Center for \\ Metabolic Disease, University Hospital Gasthuisberg, 3000 Leuven, Belgium
}

\begin{abstract}
Carbohydrate-deficient glycoprotein syndromes (CDGS) type I are a group of genetic diseases characterized by a deficiency of $\mathrm{N}$-linked protein glycosylation in the endoplasmic reticulum. The majority of these CDGS patients have phosphomannomutase (PMM) deficiency (type A). This enzyme is required for the synthesis of GDP-mannose, one of the substrates in the biosynthesis of the dolichol-linked oligosaccharide $\mathrm{Glc}_{3} \mathrm{Man}_{9} \mathrm{GlcNAc}_{2}$. This oligosaccharide serves as the donor substrate in the $\mathrm{N}$-linked glycosylation process. We report on the biochemical characterization of a novel CDGS type I in fibroblasts of four related patients with normal PMM activity but a strongly reduced ability to synthesize glucosylated dolichol-linked oligosaccharide leading to accumulation of dolichol-linked $\mathrm{Man}_{9} \mathrm{GlcNAc}_{2}$. This deficiency in the synthesis of dolichol-linked $\mathrm{Glc}_{3} \mathrm{Man}_{9} \mathrm{GlcNAc}_{2}$ oligosaccharide explains the hypoglycosylation of serum proteins in these patients, because nonglucosylated oligosaccharides are suboptimal substrates in the protein glycosylation process, catalyzed by the oligosaccharyltransferase complex. Accordingly, the efficiency of N-linked protein glycosylation was found to be reduced in fibroblasts from these patients. (J. Clin. Invest. 1998. 102:647-652.) Key words: glycosylation - dolichol - oligosaccharyltransferase $\cdot$ endoplasmic reticulum
\end{abstract}

\section{Introduction}

Carbohydrate-deficient glycoprotein syndromes (CDGS) ${ }^{1}$ are a group of genetic diseases mostly associated with major involvement of the central nervous system (1-3). Patients with

The contributions of the first two authors should be considered as equivalent.

L. Borsig's present address is Glycobiology Program, UCSD Cancer Center, and the Division of Cellular and Molecular Medicine, University of California San Diego, La Jolla, CA 92093-0687.

Address correspondence to Jaak Jaeken, Center for Metabolic Disease, University Hospital Gasthuisberg, Herestraat 49, 3000 Leuven, Belgium. E-mail:Jo.Vencken@uz.kuleuven.ac.be

Received for publication 17 November 1997 and accepted in revised form 28 May 1998.

J. Clin. Invest.

(C) The American Society for Clinical Investigation, Inc. 0021-9738/98/08/0647/06 \$2.00

Volume 102, Number 4, August 1998, 647-652

http://www.jci.org these syndromes have a worldwide occurrence $(4,5)$. The diagnosis is mostly made by isoelectro focusing of serum transferrin showing an altered cathodal migration of transferrin due to undersialylation of the protein (6). Two distinct types of CDGS have been well characterized due to different glycosylation pattern of serum transferrin. The CDGS type II has been described in two patients and was found to be caused by a deficiency of the Golgi-processing enzyme $N$-acetylglucosaminyltransferase II $(1,4,7,8)$. The much more common type I CDGS is characterized by a partial or complete absence of entire glycans on glycoproteins (9-11), and it is assumed that hypoglycosylation of proteins is the cause for the diverse symptoms observed in CDGS type I patients. This reduced glycosylation efficiency is best explained by an abnormal biosynthesis of the dolichol-linked oligosaccharide, the substrate of the $\mathrm{N}$-glycosylation process in the endoplasmic reticulum (12-14). The assembly of the dolichol-linked oligosaccharide occurs at the ER membrane, where nucleotide-activated and dolichol-linked sugars serve as substrates (15). Indeed, a deficiency in phosphomannomutase (PMM) activity, which is required for the biosynthesis of the sugar donor guanosine diphosphate (GDP)-mannose, was found in $~ 80 \%$ of CDGS type I patients, and a number of mutations in the PMM2 locus have been identified $(16,17)$. For other CDGS type I cases, a reduced polyprenol reductase activity was suggested to be the primary defect; however, a reduced phosphomannomutase activity was also observed in cells of these patients (18). Recently, the CDGS type Ib was described and assigned to a deficiency in phosphomannoisomerase, an enzyme required in GDP-mannose biosynthesis before phosphomannomutase (19).

In this report, we present biochemical data on four related patients with the CDGS type I serum sialotransferrin pattern but normal levels of PMM activity. The clinical symptomatology was milder as compared with CDGS patients with impaired PMM activity. Fibroblasts from all four patients showed a specific deficiency in the assembly of the dolichol-linked oligosaccharide, namely an impaired glucosylation of the dolichollinked oligosaccharide leading to accumulation of dolichylpyrophosphate-linked $\mathrm{Man}_{9} \mathrm{GlcNAc}_{2}$.

\section{Methods}

Patients and cells. Fibroblasts and sera from four members of an inbred Dutch family (3 girls, 1 boy; 3-7 years of age), as well as from sex- and age-matched controls were studied. The most striking clini-

1. Abbreviations used in this paper: CDGS, carbohydrate-deficient glycoprotein syndromes; DMEM, Dulbecco's minimal medium; LLO, lipid-linked oligosaccharides; PMM, phosphomannomutase. 
cal feature of these patients was a neurological involvement but much less pronounced as compared with previously reported CDGS patients. Detailed clinical features and laboratory data are reported elsewhere (de Rijk-van Andel, manuscript in preparation). Fibroblasts were cultivated in Dulbecco's minimal medium (DMEM/F12; Gibco BRL, Grand Island, NY) supplemented with $10 \%$ FCS.

Isoelectro focusing of serum transferrin. Isoelectro focusing of serum transferrin was performed as described (6).

Metabolic labeling of fibroblasts with $\left[{ }^{3} \mathrm{H}\right]$-mannose and preparation of dolichol-linked oligosaccharides. Subconfluent cultures of fibroblasts grown in DMEM/F12 medium with $5 \%$ dialyzed FCS on 24-cm plates were rinsed once with PBS and incubated for $90 \mathrm{~min}$ in Optimem medium (Gibco BRL, Grand Island, NY) supplemented with $0.5 \mathrm{mM}$ glucose (low glucose), $5 \%$ dialyzed FCS, and $2 \mathrm{mM}$ glutamine. After this incubation, cells were labeled with $150 \mu \mathrm{Ci}$ $\left[{ }^{3} \mathrm{H}\right]$-mannose $(20 \mathrm{Ci} / \mathrm{mmol}$; ICN Pharmaceuticals) for $60 \mathrm{~min}$ in the same low glucose medium. After removal of radioactive medium, cells were washed twice with ice-cold PBS and collected with a rubber policeman in $10 \mathrm{ml}$ of ice-cold $0.1 \mathrm{mM}$ Tris- $\mathrm{HCl} \mathrm{pH} \mathrm{7.4:} \mathrm{methanol}$ $(8: 3, \mathrm{vol} / \mathrm{vol})(20)$. To the suspension, $10.9 \mathrm{ml}$ chloroform was added; the mixture was extensively vortexed and centrifuged. Cells were collected at the interphase of the upper aqueous phase and the lower organic phase and resuspended in chloroform:methanol:water (10:10:3, $\mathrm{vol} / \mathrm{vol} / \mathrm{vol}$ ). Extraction of dolichol-linked oligosaccharides was performed as described (21). The radiolabeled oligosaccharides were analyzed by HPLC (22). The different species of oligosaccharides were identified by comigration with defined oligosaccharides derived from specific yeast mutant strains, which accumulate characterized intermediates in the lipid-linked oligosaccharides (LLO) biosynthesis.

Phosphomannomutase assay. The phosphomannomutase assay was performed as described elsewhere (16).

Metabolic labeling of fibroblasts with $\left[{ }^{3} \mathrm{H}\right]$ mannose and $\left[{ }^{35} \mathrm{~S}\right] \mathrm{me}$ thionine. Fibroblasts were cultured in DMEM/F12 medium with $5 \%$ dialyzed FCS in T75 flasks. Cells were metabolically labeled for 60 min with $\left[{ }^{3} \mathrm{H}\right]$ mannose $(16 \mu \mathrm{Ci} / \mathrm{ml})$ and $\left[{ }^{35} \mathrm{~S}\right]$ methionine $(3 \mu \mathrm{Ci} / \mathrm{ml})$ in methionine-free MEM medium containing $0.5 \mathrm{mM}$ glucose and $5 \%$ dialyzed FCS. The procedure to determine the incorporation rate of $\left[{ }^{3} \mathrm{H}\right]$-mannose and $\left.{ }^{35} \mathrm{~S}\right]$ methionine into protein has been described (12).

\section{Results}

Type I serum sialotransferrin pattern but normal phosphomannomutase activity in patient fibroblasts. Four children of healthy consanguineous parents presented moderate symptoms similar to the carbohydrate-deficient glycoprotein syndrome (de Rijkvan Andel, manuscript in preparation). Identical twin girls (patients $\mathrm{J}$ and $\mathrm{N}$, at five years of age) and two other related children, patient $\mathrm{R}$, a seven-year-old boy and his two-year-old sister L, were studied. In all four cases similar clinical symptoms were observed; however, much less pronounced neurological involvement as compared with previously reported CDGS patients was noted (de Rijk-van Andel, manuscript in preparation). We analyzed the electrophoretic mobility of serum transferrin in one of the patients (Fig. 1). In healthy individuals, the major transferrin species is the tetrasialo-transferrin with low amounts of trisialo and pentasialo-forms (lanes 1 and 5 ; 9). In contrast, analysis of serum transferrin from patient $\mathrm{J}$ revealed that the disialo- (two) and tetrasialo-forms (four) were the most abundant glycoforms; low amounts of asialo-transferrin (zero) were also detected (Fig. 1, lane 2). These alterations in the transferrin profile are very similar to those observed in a CDGS type I patient with a known deficiency in phosphomannomutase activity (Fig. 1, lane 3). However, the pattern of serum transferrin is clearly different from

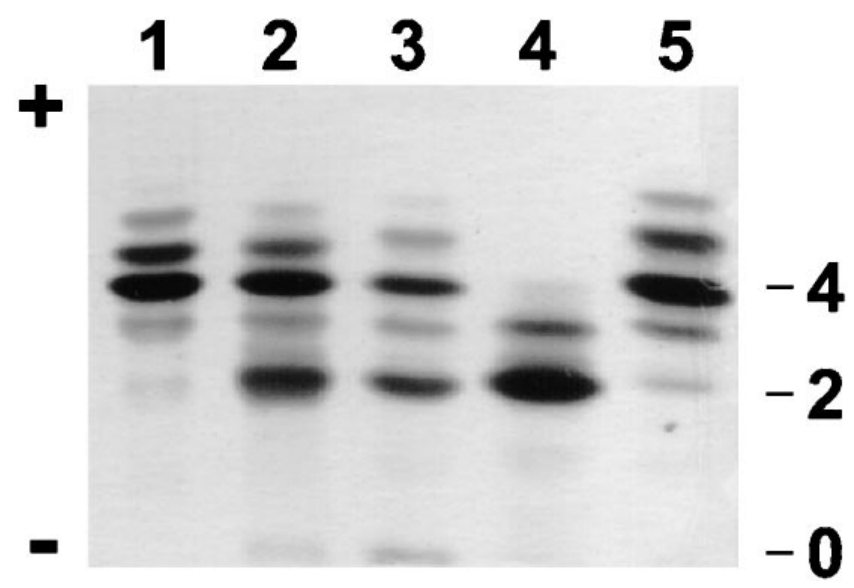

Figure 1. Isoelectro focusing of transferrin immunoisolated from serum of CDGS patients and healthy individuals. Transferrin from CDGS patients and healthy individuals was purified and saturated with iron, then subjected to isoelectro focusing electrophoresis and stained after electrophoresis as indicated in Methods. Lane 1 and 5, transferrin from healthy individuals; lane 2, one of the present patients (pt J); lane 3, CDGS type I patient (phosphomannomutase deficiency); lane 4, CDGS type II patient ( $N$-acetylglucosaminyltransferase II deficiency). The numbers given at the right indicate the number of sialic acid residues present on each sialotransferrin fraction.

the one observed in serum from a CDGS type II patient with a defect in $N$-acetylglucosaminyltransferase II (Fig. 1, lane 4; 8).

The hypoglycosylation of transferrin observed in a majority of CDGS type I patients is caused by a strongly reduced phosphomannomutase activity $(3,16,17)$. We measured the PMM activity in leukocytes of one of the four patients (patient $\mathrm{J}: 2.3$ $\mathrm{mU} / \mathrm{mg}$ protein; see also Fig. 1, lane 2) and compared it with the PMM activity found in leukocytes either from healthy individuals (range of 2.2-6.4 mU/mg protein) or CDGS type I patients with PMM deficiency (range of $0-1.4 \mathrm{mU} / \mathrm{mg}$ protein; CDGS type I patient analyzed in Fig. 1, lane $3: 0.1 \mathrm{mU} / \mathrm{mg}$ protein). Due to the normal levels of PMM activity found, we conclude that these consanguineous patients present a novel type of carbohydrate deficient glycoprotein syndrome type I characterized by the hypoglycosylation of transferrin but normal levels of PMM activity.

Altered biosynthesis of the dolichol-linked oligosaccharide in patient fibroblasts. Hypoglycosylation of transferrin as well as the almost equal distribution of disialoform (two) and tetrasialoform (four) of transferrin and low amounts of asialotransferrin (zero) in the present patients is best explained by a reduced efficiency of $\mathrm{N}$-linked glycosylation of proteins in the endoplasmic reticulum (9). A reduced efficiency of protein glycosylation is either due to a reduced oligosaccharyltransferase activity or an impaired synthesis of the dolichol-linked oligosaccharide substrate (as in the case of the CDG type I patients). To detect alterations in the biosynthesis of the dolichol-linked oligosaccharide, we have analyzed the composition of dolichol-linked oligosaccharides in fibroblasts derived from healthy individuals and from the patients. Cells were labeled with $\left[{ }^{3} \mathrm{H}\right]$ mannose, dolichol-linked oligosaccharides were extracted, the oligosaccharides were released from the lipid car- 

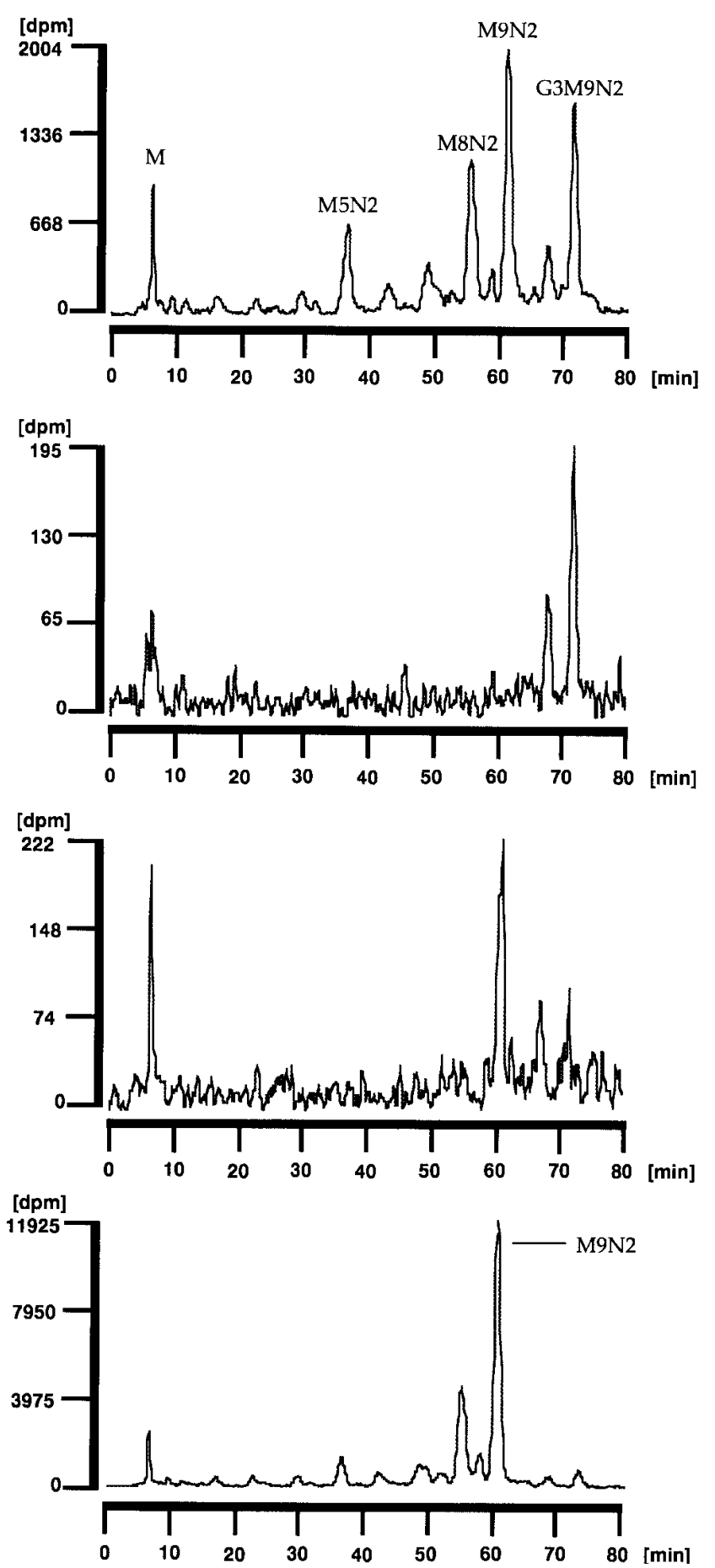

rier dolichylpyrophosphate and analyzed by HPLC. This type of analysis makes it possible to separate the individual biosynthetic intermediates of the dolichol-linked oligosaccharides. As markers for the different oligosaccharides, we used oligosaccharides derived from yeast strains deficient in defined steps of the assembly pathway. In such strains, the substrate of the affected reaction accumulates (23-26). In fibroblasts derived from healthy individuals, we detected predominantly the fully assembled dolichol-linked oligosaccharide consisting of three glucose-, nine mannose-, and two $N$-acetylglucosa-
A

standard (yeast)

B

normal

fibroblasts

C

patient $\mathrm{N}$

fibroblasts

D

yeast $\Delta$ alg 5 cells (MangGlcNAc 2 )

mine-residues $\left(\mathrm{Glc}_{3} \mathrm{Man}_{9} \mathrm{GlcNAc}_{2} ; 15\right)$. Small amounts of an oligosaccharide lacking the terminal $\alpha$-1,2-linked glucose $\left(\mathrm{Glc}_{2} \mathrm{Man}_{9} \mathrm{GlcNAc}_{2}\right)$ were also detected (Fig. $\left.2 \mathrm{~B}\right)$. In contrast, the dolichol-linked oligosaccharides accumulating in fibroblasts from the present patients were different: a major fraction of the oligosaccharides consisted of $\mathrm{Man}_{9} \mathrm{GlcNAc}_{2}$, lacking the three terminal glucose residues (Fig. $2 C$ and Table I). This was confirmed by comparison of the retention time by using LLO from a $\Delta a \lg 5$ yeast strain lacking dolichylphosphoglucose synthase activity and therefore accumulating $\mathrm{Man}_{9^{-}}$ 
Table I. [ $\left.{ }^{3} H\right]$ Mannose Incorporation into Dolichol-linked Oligosaccharides in Fibroblasts Indicating the Relative Amounts of the Dolichol-linked Oligosaccharide Species

\begin{tabular}{ccccccc}
\hline \multirow{2}{*}{ Subjects } & Experiment & $\begin{array}{c}\% \\
\mathrm{M}_{8} \mathrm{~N}_{2}\end{array}$ & $\begin{array}{c}\% \\
\mathrm{M}_{9} \mathrm{~N}_{2}\end{array}$ & $\begin{array}{c}\% \\
\mathrm{G}_{1} \mathrm{M}_{9} \mathrm{~N}_{2}\end{array}$ & $\begin{array}{c}\% \\
\mathrm{G}_{2} \mathrm{M}_{9} \mathrm{~N}_{2}\end{array}$ & $\begin{array}{c}\% \\
\mathrm{G}_{3} \mathrm{M}_{9} \mathrm{~N}_{2}\end{array}$ \\
\hline Patient N & 1 & 35 & 49 & - & - & 16 \\
& 2 & 30 & 70 & - & - & - \\
& 3 & - & 61 & - & 23 & 16 \\
Patient J & 1 & 19 & 60 & - & - & 21 \\
& 2 & - & 31 & - & 22 & 47 \\
Patient L & 1 & - & 43 & - & - & 57 \\
Patient R & 1 & - & 44 & - & - & 55 \\
Controls & 1 & - & - & - & 23 & 33 \\
& 2 & - & - & - & 33 & 67 \\
& 3 & - & - & - & 35 & 65 \\
\hline
\end{tabular}

$\operatorname{GlcNAc}_{2}(26,27$; Fig. $2 D)$. As reported in Fig. $2 C$ and $D$, oligosaccharide species derive either from patient $\mathrm{N}$ or the $\Delta$ alg 5 yeast strain had the same retention time. The accumulation of $\mathrm{Man}_{9} \mathrm{GlcNAc}_{2}$ was observed in the four patients analyzed; however, the relative amount of this oligosaccharide species was found to vary between assays of the cells from the same patient as well as between the cells derived from the four patients (Table I). Beside the predominant $\mathrm{Man}_{9} \mathrm{GlcNAc}_{2}$ oligosaccharide, we detected variable amounts of $\mathrm{Glc}_{3} \mathrm{Man}_{9} \mathrm{GlcNAc}_{2}$ and $\mathrm{Glc}_{2} \mathrm{Man}_{9} \mathrm{GlcNAc}_{2}$ oligosaccharides, suggesting only a partial deficiency in the assembly of the complete dolichollinked oligosaccharide in these cells. But most importantly, we did not observe the accumulation of $\mathrm{Man}_{9} \mathrm{GlcNAc}_{2}$ oligosaccharide in non-CDGS cells (Table I). These results show that fibroblasts derived from the present patients have a strongly reduced capacity to glucosylate dolichol-linked oligosaccharides. This defect most likely explains the hypoglycosylation of glycoproteins in these patients because nonglucosylated oligosaccharides are suboptimal substrates for the oligosaccharyltransferase and are therefore transferred to proteins with a reduced efficiency $(20,28)$.

Altered efficiency of $\mathrm{N}$-linked protein glycosylation in patient fibroblasts. To confirm our hypothesis that the altered biosynthesis of the LLO in the patients affects N-linked protein glycosylation, we measured the incorporation of $\left[{ }^{3} \mathrm{H}\right] \mathrm{man}-$ nose into glycoproteins of fibroblasts derived from CDGS patients and control individuals. To determine the efficiency of $\mathrm{N}$-linked protein glycosylation, we compared the incorporation of $\left[{ }^{3} \mathrm{H}\right]$ mannose with that of $\left[{ }^{35} \mathrm{~S}\right]$ methionine into TCAprecipitable material (Fig. 3). Fibroblasts from patient N (glucosylation deficiency) and a PMM-deficient CDGS type I patient incorporated significantly less mannose into proteins as compared with control fibroblasts. Incorporation of $\left[{ }^{3} \mathrm{H}\right]$ mannose into glycoproteins is affected more strongly in PMM-deficient CDGS type I cells (fivefold reduction) as compared with fibroblasts derived from the glucosylation-deficient patients (threefold reduction). As reported previously $(12,14)$, we observed a strongly reduced incorporation of $\left[{ }^{3} \mathrm{H}\right]$ mannose into LLO in PMM-deficient cells (data not shown). However, the extent of $\left[{ }^{3} \mathrm{H}\right]$ mannose incorporation into LLO was not sig- nificantly affected in the fibroblasts of glucosylation-deficient patient $\mathrm{N}$ (Fig. 2). We conclude that the reduced incorporation of $\left[{ }^{3} \mathrm{H}\right]$ mannose into glycoproteins in glucosylation-deficient CDGS fibroblasts is due to a reduced transfer rate of the oligosaccharide from the lipid carrier dolichylpyrophosphate to protein. These results support our hypothesis that the hypoglycosylation of glycoproteins in this novel CDGS type I is the result of impaired glucosylation in LLO biosynthesis.

\section{Discussion}

The patients studied represent a novel subtype of the CDGS type I. As described for other cases of CDGS type I, an altered $\mathrm{N}$-linked glycosylation process was observed in these patients. This alteration is reflected by a specific hypoglycosylation pattern of serum transferrin. A similar distribution of transferrin glycoforms is also observed in CDGS type I patients affected in PMM activity and is compatible with the hypothesis that hypoglycosylation of proteins results from a reduced efficiency of the $\mathrm{N}$-linked glycosylation process in the endoplasmic reticulum. In contrast to patients with CDGS type I syndromes, normal PMM activity was observed in the patients analyzed in this study. Therefore, we determined the composition of dolichollinked oligosaccharides in normal and patient fibroblasts and found that the intermediate $\mathrm{Man}_{9} \mathrm{GlcNAc}_{2}$ of the dolichollinked oligosaccharide biosynthesis accumulated in all four different patient cell lines tested. The accumulation of this biosynthetic intermediate was not detected in control fibroblasts. However, we also observed low and variable amounts of complete $\mathrm{Glc}_{3} \mathrm{Man}_{9} \mathrm{GlcNAc}_{2}$ oligosaccharide in the patient-derived cells lines, suggesting a partial deficiency in the synthesis of glucosylated oligosaccharide. A variability in the relative amount of dolichol-linked oligosaccharide species has been observed before $(12,14)$; however, no explanation to account for this observation could be given. A defective biosynthesis of the dolichol-linked oligosaccharide explains the hypoglycosylation phenotype observed in these patients. As proposed for the PMM-deficient CDGS type I patients, incomplete dolichol-linked oligosaccharide is assembled in the ER and serves

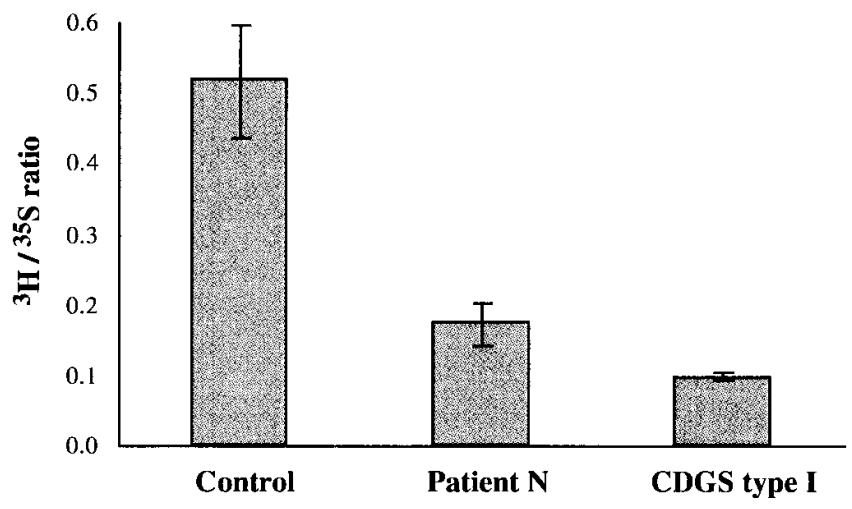

Figure 3. Incorporation of $\left[{ }^{3} \mathrm{H}\right]$ mannose and $\left[{ }^{35} \mathrm{~S}\right]$ methionine into protein. Incorporation of radioactivity in TCA-insoluble material was determined in fibroblasts after metabolic labeling for $60 \mathrm{~min}$. The ratio of $\left[{ }^{3} \mathrm{H}\right]$ vs. $\left[{ }^{35} \mathrm{~S}\right]$ incorporation is shown. The mean value of at least three independent experiments is given. Standard deviations are indicated by vertical bars. 
as a suboptimal substrate for the oligosaccharyltransferase reaction $(12,13)$. Studies both in higher eukaryotic cell lines $(20$, $28,29)$ and in yeast $(23-26,30)$ have shown that incompletely assembled dolichol-linked oligosaccharide can be transferred to protein, albeit with reduced efficiency. Indeed, we observe a reduced $\left[{ }^{3} \mathrm{H}\right]$ mannose incorporation into glycoproteins in both glucosylation-deficient and PMM-deficient CDGS type I fibroblasts. This low transfer efficiency results in underglycosylated proteins producing a phenotype also observed in CDGS patients.

At present, we can only speculate about the primary defect in these patient cells. In yeast, both a deficiency in the DolP-Glc (Alg5p) synthesizing enzyme or in the first Dol-P-Glcdependent glucosyltransferase (Alg6p; 24, 26, 27) lead to accumulation of dolichol-linked $\mathrm{Man}_{9} \mathrm{GlcNAc}_{2}$. Determination of these two enzyme activities or the isolation of the corresponding genes will make it possible to define the primary defect in the patient cells. Proteins involved in the assembly of the dolichol-linked oligosaccharide are highly conserved. This will allow us to isolate the appropriate human genes by using the information obtained from the homologous yeast loci.

In CDGS type I derived cells, the glycosylation of many different glycoproteins is affected (11), and for many glycoproteins, the carbohydrate moiety is essential for their activity (31). In line with this hypothesis, we observed that in glucosylation-deficient fibroblasts, the activity of the Golgi-localized $\alpha-2,6$ sialyltransferase is significantly reduced (Borsig, L., and E.G. Berger, unpublished observations). Indeed, glycosylation of $\alpha-2,6$ sialyltransferase was reported to be essential for enzymatic activity (32).

It is interesting to note that the PMM-deficient CDGS type I patients and the patients of this study differ in their clinical symptoms; however, the hypoglycosylation of serum proteins as visualized for transferrin is similar (see Fig. 1). Our results offer an explanation to account for this observation. A PMM deficiency leads to reduced biosynthesis of GDP-mannose, which not only affects the process of N-linked glycosylation in the ER but also the biosynthesis of GDP-fucose, the donor substrate for the Golgi-localized fucosyltransferases, as well as the biosynthesis of the GPI anchor, where four mannose residues are required to build up the glycolipid anchor (33). In contrast, a deficiency in glucosylation of the dolichol-linked oligosaccharide does only affect the N-linked glycosylation process and possibly the quality control mechanism of $N$-glycoprotein folding (34). The recently identified CDGS type Ib, which is caused by a deficiency in phosphomannose isomerase activity, again differs in the clinical symptoms observed in such patients but also results in a similar hypoglycosylation of glycoproteins (19). The variety of clinical representations of deficiencies in the $\mathrm{N}$-linked glycoprotein biosynthesis suggests that other disorders might be caused by hypoglycosylation. An extended screening of glycosylation deficiencies might lead to their detection.

\section{Acknowledgments}

We thank Bea Berger, André Dinter, and Thierry Hennet for the help with cell cultivation; Emile Van Schaftingen for the PMM measurements. This work was supported by grants from the Fund for Scientific Research (J.J.) and the Swiss National Science Foundation (grant 3100-46836.96 to E.G.B. and grant 3100-040350.94 to M.A.).

\section{References}

1. Jaeken, J., H. Stibler, and B. Hagberg. 1991. The carbohydrate-deficient glycoprotein syndrome. A new inherited multisystemic disease with severe nervous system involvement. Acta. Paediatr. Scand. Suppl. 375:1-71.

2. Jaeken, J., H. Carchon, and H. Stibler. 1993. The carbohydrate-deficient glycoprotein syndromes: pre-Golgi and Golgi disorders? Glycobiology. 3:423428

3. Jaeken, J., G. Matthijs, R. Barone, and H. Carchon. 1997. Carbohydrate deficient glycoprotein (CDG) syndrome type I. J. Med. Genet. 34(1):73-76.

4. Ramaekers, V.T., H. Stibler, J. Kint, and J. Jaeken. 1991. A new variant of the carbohydrate deficient glycoproteins syndrome. J. Inherit. Metab. Dis. 14: $385-388$.

5. Jaeken, J., P. De Cock, H. Stibler, C. Van Geet, J. Kint, V. Ramaekers, and H. Carchon. 1993. Carbohydrate-deficient glycoprotein syndrome type II. J. Inherit. Metab. Dis. 16:1041.

6. Jaeken, J., H.G. van Eijk, C. van der Heul, L. Corbeel, R. Eeckels, and E. Eggermont. 1984. Sialic acid-deficient serum and cerebrospinal fluid transferrin in a newly recognized genetic syndrome. Clin. Chim. Acta. 144:245-247.

7. Jaeken, J., H. Schachter, H. Carchon, P. De Cock, B. Coddeville, and G. Spik. 1994. Carbohydrate deficient glycoprotein syndrome type II: a deficiency in Golgi localised N-acetyl-glucosaminyltransferase II. Arch. Dis. Child. 71: 123-127.

8. Tan, J., J. Dunn, J. Jaeken, and H. Schachter. 1996. Mutations in the MGAT2 gene controlling complex N-glycan synthesis cause carbohydrate-deficient glycoprotein syndrome type II, an autosomal recessive disease with defective brain development. Am. J. Hum. Genet. 59:810-817.

9. Yamashita, K., H. Ideo, T. Ohkura, K. Fukushima, I. Yuasa, K. Ohno, and K. Takeshita. 1993. Sugar chains of serum transferrin from patients with carbohydrate deficient glycoprotein syndrome: evidence of asparagineN-linked oligosaccharide transfer deficiency. J. Biol. Chem. 268:5783-5789.

10. Yamashita, K., T. Ohkura, H. Ideo, K. Ohno, and M. Kanai. 1993. Electrospray ionization-mass spectrometric analysis of serum transferrin isoforms in patients with carbohydrate-deficient glycoprotein syndrome. J. Biochem. (Tokyo). 114:766-769.

11. Krasnewich, D.M., G.D. Holt, M. Brantly, F. Skovby, J. Redwine, and W.A. Gahl. 1995. Abnormal synthesis of dolichol-linked oligosaccharides in carbohydrate-deficient glycoprotein syndrome. Glycobiology. 5:503-510.

12. Powell, L.D., K. Paneerselvam, R. Vij, S. Diaz, A. Manzi, N. Buist, H. Freeze, and A. Varki. 1994. Carbohydrate-deficient glycoprotein syndrome: not an N-linked oligosaccharide processing defect, but an abnormality in lipidlinked oligosaccharide biosynthesis? J. Clin. Invest. 94:1901-1909.

13. Panneerselvam, K., and H.H. Freeze. 1996. Mannose corrects altered $\mathrm{N}$-glycosylation in carbohydrate-deficient glycoprotein syndrome fibroblasts. $J$. Clin. Invest. 97:1478-1487.

14. Körner, C., L. Lehle, and K. von Figura. 1998. Abnormal synthesis of mannose 1-phosphate derived carbohydrates in carbohydrate-deficient glycoprotein syndrome type I fibroblasts with phosphomannomutase deficiency. Glycobiology. 8:165-171.

15. Kornfeld, R., and S. Kornfeld. 1985. Assembly of asparagine-linked oligosaccharides. Annu. Rev. Biochem. 54:631-664.

16. Van Schaftingen, E., and J. Jaeken. 1995. Phosphomannomutase deficiency is a cause of carbohydrate-deficient glycoprotein syndrome type I. FEBS Lett. 377:318-320.

17. Matthijs, G., E. Schollen, E. Pardon, M. Veiga Da Cunha, J. Jaeken, J.J. Cassiman, and E. Van Schaftingen. 1997. Mutations in PMM2, a phosphomannomutase gene on chromosome 16p13, in carbohydrate-deficient glycoprotein type I syndrome (Jaeken syndrome). Nat. Genet. 16:88-92.

18. Ohkura, T., K. Fukushima, A. Kurisaki, H. Sagami, K. Ogura, K. Ohno, S. Hara Kuge, and K. Yamashita. 1997. A partial deficiency of dehydrodolichol reduction is a cause of carbohydrate-deficient glycoprotein syndrome type I. $J$. Biol. Chem. 272:6868-6875.

19. Niehues, R., M. Hasilik, G. Alton, C. Körner, M. Schiebe-Sukumar, H.G. Koch, K.-P. Zimmer, R. Wu, E. Harms, K. Reiter, et al. 1998. Carbohydrate-deficient glycoprotein syndrome type Ib: phosphomannose isomerase deficiency and mannose therapy. J. Clin. Invest. 101:1414-1420.

20. Ermonval, M., R. Cacan, K. Gorgas, I.G. Haas, A. Verbert, and G. Buttin. 1997. Differential fate of glycoproteins carrying a monoglucosylated form of truncated $\mathrm{N}$-glycan in a new CHO line, MadIA214, selected for a thermosensitive secretory defect. J. Cell Sci. 110:323-336.

21. Burda, P., and M. Aebi. 1998. The ALG10 locus of Saccharomyces cerevisiae encodes the $\alpha-1,2$ glucosyltransferase of the endoplasmic reticulum: the terminal glucose of the lipid-linked oligosaccharide is required for efficient N-linked glycosylation. Glycobiology. 8:455-462.

22. Zufferey, R., R. Knauer, P. Burda, I. Stagljar, S. te Heesen, L. Lehle, and M. Aebi. 1995. STT3, a highly conserved protein required for yeast oligosaccharyl transferase activity in vivo. EMBO J. 14:4949-4960.

23. Burda, P., S. te Heesen, A. Brachat, A. Wach, A. Düsterhöft, and M. Aebi. 1996. Stepwise assembly of the lipid-linked oligosaccharide in the endoplasmic reticulum of Saccharomyces cerevisiae: identification of the $A L G 9$ gene encoding a putative mannosyl transferase. Proc. Natl. Acad. Sci. USA. 93:71607165 . 
24. Reiss, G., S. te Heesen, J. Zimmerman, P.W. Robbins, and M. Aebi. 1996. Isolation of the ALG6 locus of Saccharomyces cerevisiae required for glucosylation in the N-linked glycosylation pathway. Glycobiology. 6:493-498.

25. Stagljar, I., S. te Heesen, and M. Aebi. 1994. New phenotype of mutations deficient in glucosylation of the lipid-linked oligosaccharide: cloning of the ALG8 locus. Proc. Natl. Acad. Sci. USA. 91:5977-5981.

26. te Heesen, S., L. Lehle, A. Weissmann, and M. Aebi. 1994. Isolation of the $A L G 5$ locus encoding the UDP-glucose: dolichyl-phosphate glucosyltransferase from Saccharomyces cerevisiae. Eur. J. Biochem. 224:71-79.

27. Runge, K.W., T.C. Huffaker, and P.W. Robbins. 1984. Two yeast mutations in glucosylation steps of the asparagine glycosylation pathway. J. Biol. Chem. 259:412-417.

28. Murphy, L.A., and R.G. Spiro. 1981. Transfer of glucose to oligosaccharide-lipid intermediates by thyroid microsomal enzymes and its relationship to the N-glycosylation of proteins. J. Biol. Chem. 256:7487-7494.
29. Stoll, J., R. Cacan, A. Verbert, and S.S. Krag. 1992. Lec15 cells transfer glucosylated oligosaccharides to protein. Arch. Biochem. Biophys. 299:225-231.

30. Aebi, M., J. Gassenhuber, H. Domdey, and S. te Heesen. 1996. Cloning and characterization of the ALG3 gene of Saccharomyces cerevisiae. Glycobiology. 6:439-444.

31. Varki, A. 1993. Biological roles of oligosaccharides-all of the theories are correct. Glycobiology. 3:97-130.

32. Fast, D.G., J.C. Jamieson, and G. McCaffrey. 1993. The role of the carbohydrate chains of Gal beta-1,4-GlcNAc alpha 2,6-sialyltransferase for enzyme activity. Biochim. Biophys. Acta. 1202:325-330.

33. Ferguson, M.A.J. 1992. Glycosyl-phosphatidylinositol membrane anchors: the tale of a tail. Biochem. Soc. Trans. 20:243-256.

34. Hammond, C., and A. Helenius. 1995. Quality control in the secretory pathway. Curr. Opin. Cell Biol. 7:523-529. 